\title{
CONE)-(oES
}

CIÊNCIA E TECNOLOGIA

\section{PROGRAMA CAMINHO DA ESCOLA: IMPACTOS DA POLÍTICA EDUCACIONAL NOS ÍNDICES EDUCACIONAIS RURAIS DO ESTADO DO CEARÁ}

\author{
Valdeir lira Pessoa e Silva, Francisco Herbert lima Vasconcelos, \\ PRISCILA BARROS DAVID \\ Universidade Federal do Ceará - UFC \\ <valdeirlira@hotmail.com>,<Herbert@virtual.ufc.br>,<priscila@virtual.ufc.br> \\ DOI: 10.21439/conexoes.v15i0.2107
}

\begin{abstract}
Resumo. O artigo descreve a política pública educacional Caminho da Escola quanto à sua estruturação de criação, objetivos e características. O estudo se baseia em uma revisão bibliográfica sistemática na qual as bases de dados utilizadas foram o Google Acadêmico, Periódico Capes e a Scientific Electronic Library Online, além das legislações e documentos oficiais competentes sobre o transporte escolar brasileiro. Para a busca dos termos foi utilizado o operador booleano "or" (ou), escolhendo-se os descritores "Programa Caminho da Escola" ou "Transporte Escolar", visando buscar a integralização de como tal política influenciou a eficiência do sistema educacional do estado do Ceará e os índices educacionais estaduais em comparação com o Nordeste do Brasil. A alta adesão ao Programa Caminho da Escola trouxe benefícios aos índices educacionais das escolas rurais do estado do Ceará.
\end{abstract}

Palavras-chaves: Política pública educacional. Transporte escolar brasileiro. Programa Caminho da Escola.

\section{CAMINHO DA ESCOLA PROGRAM: IMPACT OF EDUCATIONAL POLICY ON RURAL EDUCATIONAL INDICES IN THE STATE OF CEARÁ}

\begin{abstract}
The article describes the public educational policy Caminho da Escola regarding its structuring of creation, objectives and characteristics, the study is based on a systematic bibliographic review in which the databases used were Google Scholar, Capes Period and the Scientific Electronic Library Online in addition to the legislation and official documents competent for Brazilian school transport, the search strings used were the terms "Programa Caminho da Escola" or "Transporte Escolar" in order to seek the integration of how such policy influenced the efficiency of the educational system of the State of Ceará and in the State educational indexes in comparison with the Northeast of Brazil. The high adhesion to the Caminho da Escola Program brought benefits to the educational indexes of rural schools in the State of Ceará.
\end{abstract}

Keywords: Public educational policy. Brazilian school transport. School Path Program.

\section{INTRODUÇÃO}

A Constituição de 1988, em seu inciso I do artigo 206, trata sobre "a igualdade de condições para o acesso e permanência na escola" (BRASIL, 1988), ou seja, pressupõe-se a necessidade da criação de políticas públicas educacionais como direito assegurado e que pos- sam garantir a igualdade para o acesso e a permanência de estudantes em condições de desigualdade social. Segundo o Censo Escolar de 2019, das 180 mil escolas existentes, 55 mil estão localizadas em zonas rurais, sendo necessário haver a concepção de que a vaga de matrícula em si em uma escola rural não é garantia de permanência dos estudantes, tornando, portanto, es- 
sencial o fornecimento de transporte das crianças e dos adolescentes à escola (INEP, 2020).

Conforme Egami et al. (2015), o transporte escolar é um fator essencial para o acesso dos alunos residentes da área rural à escola, uma vez que se caracteriza como um dos maiores desafios diante da falta de estrutura nas estradas e da longa distância entre a casa dos estudantes e o colégio.

A temática "Transporte Escolar" é evidenciada na Meta 7 do Plano Nacional de Educação (PNE), a qual visa atingir as metas nacionais estabelecidas pelo Índice de Desenvolvimento da Educação Básica (IDEB) até 2021, atribuindo à União a responsabilidade concomitante às necessidades dos entes federados. Os trechos 7.13 e 7.17 trazem pontos significativos sobre a importância do transporte escolar brasileiro.

\begin{abstract}
7.13) garantir transporte gratuito para todos(as) os(as) estudantes da educação do campo na faixa etária da educação escolar obrigatória, mediante renovação e padronização integral da frota de veículos, de acordo com especificações definidas pelo Instituto Nacional de Metrologia, Qualidade e Tecnologia - INMETRO, e financiamento compartilhado, com participação da União proporcional às necessidades dos entes federados, visando a reduzir a evasão escolar e o tempo médio de deslocamento a partir de cada situação local. [...]

7.17) ampliar programas e aprofundar ações de atendimento ao (à) aluno (a), em todas as etapas da educação básica, por meio de programas suplementares de material didático-escolar, transporte, alimentação e assistência à saúde (BRASIL 2014).
\end{abstract}

Atualmente, no Brasil, o Ministério da Educação por meio do Fundo Nacional de Desenvolvimento da Educação (FNDE) subsidia dois programas de transporte escolar brasileiro para a educação básica, sendo eles o "Caminho da Escola" e o "Programa Nacional de Transporte Escolar (PNATE)", os quais transferem automaticamente recursos aos estados, Distrito Federal e municípios com o objetivo de custear algumas despesas, tais como: pagamento de serviços de terceiros contratados, manutenção, impostos, licenciamento, seguro e reforma dos modais utilizados. Como o "Programa Caminho da Escola" é objeto de estudo deste artigo, iremos nos aprofundar acerca da sua discussão (FNDE 2021).

Criado em 2007, o Programa Caminho da Escola faz parte de uma ação do Plano de Desenvolvimento da Educação (PDE) e visa à redução da evasão escolar; são oferecidos aos estudantes diversos tipos de modais, tais como: ônibus, embarcações e bicicletas. A padronização dos ônibus vem crescendo a cada ano que passa e tem a finalidade de garantir a segurança dos alunos, bem como a qualidade do transporte oferecido, além de con- tribuir para que fatores econômicos favoreçam a redução dos custos dos modais comprados e haja o aumento da transparência no momento de sua compra.

A proposta do artigo é investigar como a política pública educacional "Transporte Caminho da Escola" contribuiu para alguns índices educacionais do estado do Ceará. Em consonância buscou-se realizar uma revisão sistemática integrativa sobre o transporte escolar público brasileiro, analisar dados específicos sobre a Educação Rural do Ceará, uma vez que os documentos oficiais não traziam os dados específicos das escolas estaduais rurais.

\section{FUNDAMENTAÇÃO}

Em abril de 2007, o Ministério da Educação do Brasil, visando melhorar a qualidade da Educação, lançou PDE, cujo documento tinha em sua estruturação o estabelecimento do uso de metas que seriam articuladas com o Plano de Aceleração do Crescimento (PAC). A ideia inicial do projeto constituía um conjunto de ações e programas que compreendessem desde a Educação Básica ao ensino superior (LEHER, 2007).

Criado em 2007 pelo Decreto Federal $\mathrm{n}^{\circ}$ 6.094/2007, o Plano de Metas Compromisso Todos pela Educação surgiu como "carro chefe" do PDE (SAVIANI, 2007, p. 3). Foi fundamentado por um plano de ações que articula municípios, estados e Distrito Federal em parceria com a família e a comunidade escolar, buscando a mobilização social para o aumento do ensino de qualidade. Em julho de 2008, ocorreu a adesão de $100 \%$ dos municípios brasileiros (5.563) e dos vinte e seis estados e do Distrito Federal, por meio da assinatura de termo de adesão com a proposta traduzida no termo "em compromisso", assim, estando sujeitos a vinte e oito diretrizes que foram estabelecidas no documento (BRASIL, 2007).

Estabelecido o Plano de Metas Compromisso Todos pela Educação, o IDEB foi criado como uma das metas que objetivam aferir a qualidade da Educação, sendo estas denominadas finais e intermediárias (mensuradas a cada dois anos). A adesão ao projeto é voluntária, mas "implica a assunção da responsabilidade de promover a melhoria da qualidade da educação básica em sua esfera de competência" (BRASIL, 2007). Com a adesão, a União assumiu o Plano de Ações Articuladas (PAR), visando prestar auxílio técnico e financeiro para que se tenha evoluções positivas para o IDEB. "O PAR é o conjunto articulado de ações, apoiado técnica ou financeiramente pelo Ministério da Educação, que visa ao cumprimento das metas do compromisso e à observância das suas diretrizes" (BRASIL, 2007).

A organização do PAR se constitui de 4 pilares: 1 . 

ESTADO DO CEARÁ

Gestão Educacional; 2. Formação de Professores e dos Profissionais de Serviço e Apoio Escolar; 3. Práticas Pedagógicas e Avaliação e 4. Infraestrutura Física e Recursos Pedagógicos. Cada uma das áreas irá apresentar indicadores específicos. Após os índices serem avaliados pode-se realizar um conjunto de subações ao PAR, de forma a otimizar as áreas vistas como mais críticas e garantir a qualidade das outras bem avaliadas. Com o decorrer dos anos, foi-se percebendo a necessidade da criação de subações que visassem à melhoria da qualidade do transporte escolar, que se encaixavam no pilar de número 4 do PAR, surgindo assim, o Programa Caminho da Escola, visando ao aprimoramento desse tipo de deficiência então diagnosticada (PERGHER, 2014).

O Programa Caminho da Escola foi criado pela Resolução n ${ }^{\circ}$, de 28 de março de 2007; é controlado pelo FNDE. Em 2009, foram estabelecidos objetivos ao Programa por meio do Decreto $\mathrm{n}^{\circ} 6.768$, de 11 de fevereiro de 2009 (BRASIL, 2009), definindo cinco objetivos: renovar a frota de veículos escolares; garantir segurança e qualidade ao transporte dos estudantes; padronizar e inspecionar veículos, e reduzir a evasão escolar. Estes objetivos foram criados visando garantir a permanência e o acesso dos estudantes à Educação Básica.

Segundo Pergher (2014), os estados e municípios podem adquirir veículos e embarcações padronizados para o transporte escolar por meio de recursos financeiros próprios, desde que participem do pregão eletrônico oferecido pelo FNDE, onde acontece o estabelecimento de preços de veículos padronizados que são financiados pelo Banco Nacional de Desenvolvimento Econômico e Social (BNDES); dentre os principais veículos estão ônibus, miniônibus, micro-ônibus zero quilômetro, embarcações novas e bicicletas.

Os indicadores educacionais são aqueles que atribuem valor estatístico sobre a qualidade de ensino, não levando em consideração apenas como tem sido o desempenho dos alunos, mas também os contextos social e econômico nos quais as escolas estão inseridas. Os principais indicadores educacionais atualmente são: taxa de analfabetismo, anos de escolaridade ou de estudos, escolaridade média, defasagem idade/série ou distorção série/idade, taxa de atendimento escolar, taxa de escolarização líquida, taxa de evasão, taxa de reprovação, IDEB. O trecho a seguir correspondente ao art. $1^{\circ}$ da Resolução $n^{\circ} 2$, de 28 de abril de 2008, mostra a definição de Educação do Campo para a Secretaria de Educação do Estado do Ceará (SEDUC).

A Educação do Campo compreende a Educação Básica em suas etapas de Educação Infantil, Ensino Fundamental, Ensino Médio e Educação Profissional Técnica de nível médio integrada com o Ensino Médio e destina-se ao atendimento às populações rurais em suas mais variadas formas de produção da vida - agricultores familiares, extrativistas, pescadores artesanais, ribeirinhos, assentados e acampados da Reforma Agrária, quilombolas, caiçaras, indígenas e outros (BRASIL 2008a).

De uma maneira geral, a Educação do Campo teve grandes avanços quanto à legislação vigente nos últimos anos. No estado do Ceará, pode-se destacar a seguinte legislação sobre o tema: Resolução CEE/CEB n ${ }^{\circ}$ 426, de 27 de agosto de 2008, que regulamenta a Educação Básica na Escola do Campo, no âmbito do Estado do Ceará (BRASIL, 2008b).

\section{METODOLOGIA}

A metodologia foi dividida em etapas descritas a seguir:

- Realização de pesquisas exploratórias vinculadas às seguintes bases: Google Acadêmico, Periódico Capes e Scientific Eletronic Library Online. Foram desenvolvidas as buscas a partir do operador booleano or (ou) "Programa Caminho da Escola" or "Transporte Escolar" or "Educação Rural".

- Como base de dados do Programa "Caminho da Escola”, foram analisados as informações públicas emitidas pelo FNDE em parceria com a Universidade Federal de Goiás (UFG). Os documentos foram denominados: Caracterização e avaliação do transporte escolar do Brasil (volume 1) (UFG. 2018b) e Avaliação nacional do Programa Caminho da Escola: avaliação de impacto (volume 2) (UFG, 2018a).

- Os documentos fornecidos pelo FNDE consistem em consulta pública com a avaliação do transporte escolar brasileiro e Programa Caminho da Escola. A consulta está baseada na opinião de todos os gestores educacionais estaduais. Responderam à pesquisa 44,48\% dos gestores em um nível de confiança de $95 \%$, com um erro amostral de $\pm 5 \%$, ao mesmo tempo foram consultados conselheiros dos Conselhos de Acompanhamento e Controle Social (CACS/Fundeb), obtendo a participação de $47,4 \%$ dos conselheiros, mostrando um resultado com alto nível de segurança, $98 \%$ e com um erro amostral de $\pm 2 \%$.

- Analisados os documentos, foram verificados quais critérios poderiam ser considerados como prioritários e significativos, para serem definidos como índices educacionais relevantes, sendo estes impactados pelo Programa. A definição dos critérios estabelecidos deu-se por meio de estudos matemáticos apresentados nos estudos fornecidos pelo FNDE. 
- Definidos os índices, a SEDUC, foi contactada, e com êxito, para a obtenção dos dados educacionais necessários à pesquisa. Os dados fornecidos pela SEDUC foram: Taxa de matrícula, Taxa de abandono, IDEB anos iniciais, IDEB anos finais. Os dados fornecidos podem ser acessados através do seguinte link: <https://drive.google.com/file/ d/147S8mex79VTU28QvuK0UIqBA9neKp08q/ view?usp=sharing $>$

- A avaliação dos dados do Programa Caminho da Escola foi analisada concomitantemente com os índices das Escolas de Educação Rural do Estado do Ceará por gráficos e, a partir destes, deu-se a discussão dos resultados obtidos.

Os anos de 2017 e 2018 não foram avaliados, pois no primeiro ano não houve efetivação do Programa. Em 2018, os dados oficiais ainda não tinham sido divulgados pelo documento analisado.

\section{RESULTADOS E DISCUSSÕES}

O Documento denominado "Avaliação Nacional do Programa Caminho da Escola, Volume II" (UFG 2018a), presente no site do FNDE, traz resultados importantes acerca do Programa Caminho da Escola. Destaca-se o percentual de $30 \%$ em média dos municípios brasileiros nos anos de 2008 a 2016 que aderiram à pesquisa. No Ceará essa média de participação dos municípios chega a 44\%, sendo a maior média de participação entre os estados da Região Nordeste.

Um dado muito importante que também precisa ser destacado está no fato de que 99,9\% dos municípios da Região Nordeste já haviam aderido ao Programa Caminho da Escola em algum momento; isto é significativo porque comprova a adesão ao Programa e evidencia sua aceitação por parte de gestores educacionais.

\section{1 Índice de Evasão Escolar e sua Relação com o Programa Caminho da Escola}

$\mathrm{O}$ estudo realizado pelo FNDE em parceria com a Universidade Federal de Goiás (UFG), por meio dos métodos de estimação Dif - Dif, mostrou que o Programa Caminho da Escola teve um impacto na evasão escolar do Brasil. O estudo trouxe dados acerca da Evasão no Brasil e no estado do Ceará. No Brasil percebeuse que em 2007 a taxa de evasão era de 5,11\% (começo do Programa). Já em 2014, com 8 anos de Programa, a evasão nacional passou para $3,93 \%$ com uma redução de $23 \%$ (UFG, 2018a). No Ceará, no ano de 2007, a taxa de evasão perfazia 5,40\%, enquanto em 2014 esta taxa era de $4,12 \%$, ou seja, uma redução de $23 \%$, muito semelhante à taxa brasileira. Porém, ao analisar os documentos, se percebe que o Programa busca atingir principalmente escolas rurais (UFG, 2018a). Ao apresentar dados como taxa de evasão geral, é preciso cautela, pois surge a necessidade de compreensão a respeito da especificidade do público a ser trabalhado. A partir disso foram coletados os dados em parceria com a SEDUC/CE, somente das escolas rurais do Ceará, permitindo que a especificidade gere cada vez mais a legitimidade do impacto da pesquisa na taxa de evasão cearense.

Os resultados sobre a evasão escolar rural no estado do Ceará estão dispostos no gráfico da Figura 1 a seguir, no qual há um comparativo entre médias anuais brasileiras, regionais e estaduais gerais que compreendem escolas rurais e urbanas, como também resultados apenas de escolas rurais do estado do Ceará.

Figura 1: Comparação entre dados de evasão escolar Nacional, Região Nordeste, Ceará Geral, Ceará Educação Rural.

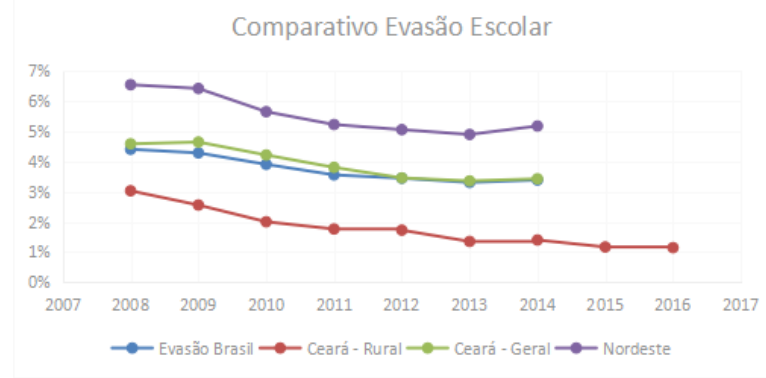

No ano de 2008, a Região Nordeste apresentava o maior índice de evasão escolar, contabilizando cerca de 6,55\% de evasão, enquanto os índices de evasão nacional e do estado do Ceará tinham valores aproximados entre $4 \%$ e $5 \%$ e a média das escolas rurais cearenses era 3\%, aproximadamente. Ao se analisar a referida situação, é possível perceber que as escolas rurais não seguiam esse padrão, e desde então apresentavam bons resultados quando comparados às demais médias.

Tomando como base o primeiro ano de Programa, 2008 e o ano de 2014, passados 8 anos de Programa, tendo dados para todos os referenciais, por isso a escolha do ano de 2014, percebeu-se uma redução da evasão de $21 \%$ no Nordeste, no Ceará de $25 \%$, no Brasil de $23 \%$ e nas escolas de Educação Rural, foco do estudo, de aproximadamente 54\%. Pode-se perceber um impacto significativo nas escolas de Educação Rural. Tal aspecto pode ser associado à adesão do estado do Ceará; o estado era o que possuía a maior média de adesão dos municípios da região Nordeste, como mostra a Tabela 1 a seguir:

Como citado anteriormente, estudar o efeito sobre 

ESTADO DO CEARÁ

Tabela 1: Percentual de municípios que aderiram ao Programa Caminho da Escola na Região Nordeste

\begin{tabular}{|l|l|l|l|l|l|l|l|l|}
\hline \multicolumn{1}{|c|}{ ESTADO } & $\mathbf{2 0 0 8}$ & $\mathbf{2 0 0 9}$ & $\mathbf{2 0 1 0}$ & $\mathbf{2 0 1 1}$ & $\mathbf{2 0 1 2}$ & $\mathbf{2 0 1 3}$ & $\mathbf{2 0 1 4}$ & Média \\
\hline Alagoas & $29 \%$ & $76 \%$ & $75 \%$ & $24 \%$ & $75 \%$ & $27 \%$ & $39 \%$ & $49,28 \%$ \\
\hline Bahia & $17 \%$ & $62 \%$ & $87 \%$ & $18 \%$ & $75 \%$ & $13 \%$ & $50 \%$ & $46 \%$ \\
\hline Ceará & $35 \%$ & $44 \%$ & $85 \%$ & $30 \%$ & $73 \%$ & $28 \%$ & $59 \%$ & $50,57 \%$ \\
\hline Maranhão & $23 \%$ & $51 \%$ & $63 \%$ & $20 \%$ & $54 \%$ & $38 \%$ & $47 \%$ & $42,28 \%$ \\
\hline Paraíba & $30 \%$ & $57 \%$ & $62 \%$ & $22 \%$ & $80 \%$ & $34 \%$ & $4 \%$ & $41,28 \%$ \\
\hline Pernambuco & $12 \%$ & $69 \%$ & $88 \%$ & $29 \%$ & $99 \%$ & $15 \%$ & $38 \%$ & $50 \%$ \\
\hline Piauí & $21 \%$ & $50 \%$ & $59 \%$ & $18 \%$ & $97 \%$ & $4 \%$ & $41 \%$ & $41,42 \%$ \\
\hline Rio Grande do Norte & $22 \%$ & $66 \%$ & $55 \%$ & $13 \%$ & $57 \%$ & $16 \%$ & $38 \%$ & $38,14 \%$ \\
\hline Sergipe & $25 \%$ & $92 \%$ & $48 \%$ & $12 \%$ & $87 \%$ & $15 \%$ & $39 \%$ & $45,42 \%$ \\
\hline
\end{tabular}

Fonte: Adaptado de FNDE (2021).

as escolas rurais estaduais do Ceará é fundamental, pois elas são as mais impactadas pelo Programa Caminho da Escola. Em uma análise bidimensional simples, relação da adesão/evasão, percebeu-se que o programa impacta significativamente para a redução da evasão dos alunos das zonas rurais. Estudos como o de Silva (2009) mostram que a adesão é a forma como critérios de distribuição e alocação dos recursos destinados ao transporte escolar, de modo a diminuir a repetência e a evasão escolar. Contudo, o autor faz um alerta importante que deve ser considerado: não adianta investir em transporte se não houver uma boa gestão dos recursos, fator que pode ser associado ao presente estudo para uma análise de mais variáveis no futuro.

A teoria quanto à falta de infraestrutura no que diz respeito ao transporte escolar rural pode influenciar índices como o da evasão escolar. A afirmação pode ser confirmada a partir de alguns estudos, por exemplo, Kusniewski (2018) observou que jovens no Paraná se sentiam desmotivados para estudar e acabavam decidindo pela evasão porque eram péssimas as condições de transporte, ou nem sequer havia, por isso decidiam pelo abandono.

\subsection{IDEB e sua Relação com o Programa Caminho da Escola}

O IDEB trata a questão de uma política de avaliação do sistema que diz respeito à qualidade da Educação, sendo realizada e monitorada de forma extensa aos órgãos de ensino, e traz um caminho de como se obter uma educação de qualidade para as unidades que são avaliadas por ele (PALUDO; SOUZA; BELTRAME, 2015) . Se faz necessário entender que as escolas rurais de educação possuem especificidades e diversas problemáticas comuns nas mais diversas regiões do país (TORRES, 2017). Em seus estudos, Carvalho et al. (2010) perceberam que alguns fatores podem influen- ciar o desempenho escolar, dentre os quais estão: os longos tempos de viagem, as grandes distâncias, os longos tempos de espera, a falta de provisão, a condição das estradas e dos veículos.

Para o estudo foram considerados os IDEB dos alunos iniciais $\left(1^{\circ}\right.$ ao $5^{\circ}$ anos) e dos anos finais $\left(6^{\circ}\right.$ ao $9^{\circ}$ anos) das escolas localizadas nas zonas rurais do Ceará. Foram coletados dados de todas as regiões do estado e as escolas conseguiram ser catalogadas com o intuito de analisá-las, uma vez que são as maiores beneficiadas com a política pública educacional Caminho da Escola.

Os resultados apontam que, à medida que os anos do Programa Caminho da Escola foram se desenvolvendo, houve um aumento da aprendizagem dos alunos rurais em todos os índices avaliados; as médias de IDEB avaliadas foram concernentes aos contextos Nacional, Região Nordeste, Ceará Geral e Escolas de Educação Rural do Ceará.

Em 2008, primeiro ano após o surgimento do Programa, se tinha o Brasil com maior média de IDEB entre as médias avaliadas, o Ceará de Educação Rural e o Nordeste com menores médias. Isso pode ser justificado exatamente pela falta de condições de estrutura. Porém, avaliou-se o processo do IDEB ao longo de 8 anos e foi observado um significativo aumento, principalmente nos IDEB do Ceará Geral e do Ceará Educação Rural, considerando apenas Educação Rural. O gráfico da Figura 2 apresenta esses resultados, como podem ser vistos a seguir:

Foram observados percentuais de aumento dos IDEB entre os anos de 2008 até 2014 para cada grupo citado anteriormente; o IDEB nacional teve um aumento de 44\%; a Região Nordeste apresentou um aumento de $65 \%$ em seu IDEB; já no Ceará ocorreu um aumento de $84 \%$ para índices gerais e de $92 \%$ para as escolas de Educação Rural. O comportamento do gráfico da Figura 2 nos mostra que o crescimento do Ceará 
Figura 2: Comparação do IDEB anos iniciais índices Nacional, Regional, Ceará Educação Geral, Ceará Educação Rural

\section{IDEB Anos Iniciais}

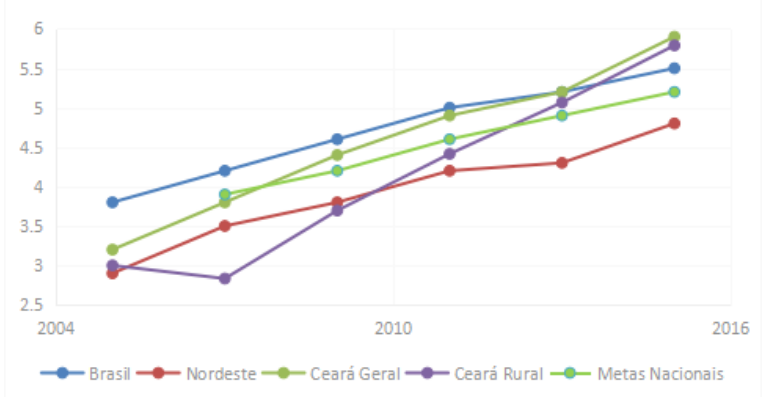

Rural é tão significativo que ultrapassa as metas estabelecidas pelo IDEB, e como consequência acaba por alavancar o Ceará Geral, uma vez que faz parte deste. A maior média de adesão verificada, na Tabela 1 leva a crer que a infraestrutura pode contribuir para o IDEB anos iniciais, como aconteceu no Estado do Ceará.

\subsection{IDEB Anos Finais e sua Relação com o Pro- grama Caminho da Escola}

Os resultados para os anos finais são semelhantes aos dos anos iniciais presentes no gráfico da Figura 2 Percebe-se que em 2007, o ano de início do Programa Caminho da Escola, os piores índices de IDEB estavam localizados na Educação Rural do Ceará, no Nordeste e no Ceará, de forma geral. Já os maiores índices se localizavam no Brasil. O gráfico da Figura 3 apresenta esses dados comparativos.

Figura 3: Comparação do IDEB anos finais índices Nacional, Regional, Ceará Educação Geral, Ceará Educação Rural

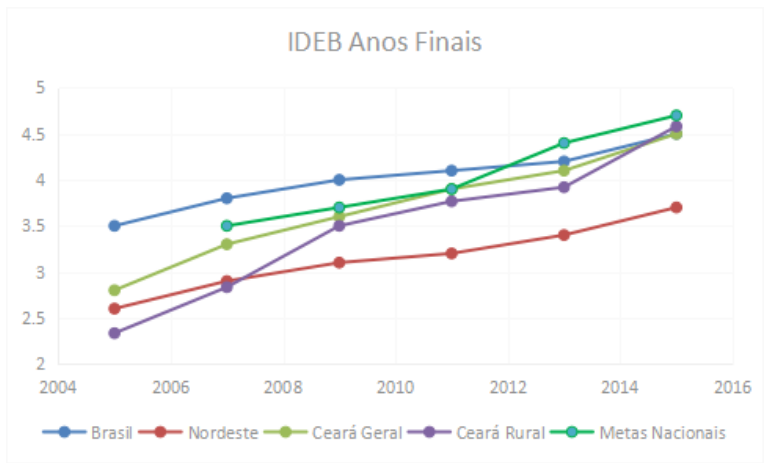

Ao elaborar o percentual de crescimento do IDEB para anos finais, foram percebidos os seguintes crescimentos: IDEB Nacional com 28,5\%; IDEB Ceará Geral totalizando 60,7\%; IDEB Nordeste perfazendo $42 \%$ e IDEB escolas rurais sinalizando $92 \%$. Ao fazermos esta relação de crescimento, podemos constatar o avanço significativo no estado do Ceará, assim como no crescimento dos anos inicias o estudo leva a crer que a taxa de adesão alta ao Programa Caminho da Escola contribuiu para o desenvolvimento dos problemas rurais no âmbito do ensino fundamental (anos finais).

\section{CONSIDERAÇÕES FINAIS}

Com o estudo realizado pôde ser depreendido que a Educação do Campo possui particularidades e especificidades que precisam ser tratadas para garantir o acesso e a permanência daqueles que participam do processo; percebeu-se, ainda, que a política pública educacional Caminho da Escola interferia em índices educacionais como a evasão e a qualidade de aprendizagem expressas pelo IDEB.

A especificidade dos dados educacionais rurais traz legitimidade quanto ao impacto do programa sobre a Educação Rural do Ceará; observou-se a queda da evasão educacional, bem como a queda da evasão nacional, regional e estadual. No que tange ao IDEB, também se observou um aumento significativo, tanto para as escolas de uma forma geral, do Ceará, como para as escolas rurais, garantindo dessa maneira que o estado do Ceará tenha grandes desenvolvimentos educacionais.

O estudo necessita de outras variáveis e de uma análise estatística mais aprofundada, para de fato garantir o impacto do Programa sobre o IDEB, tanto para os anos iniciais como para os anos finais, apesar de já ser perceptível que políticas públicas de transporte contribuem para a qualidade de vida dos estudantes, melhorando seus índices escolares, e que de maneira indireta contribuem para índices como o IDEB, que avaliam a qualidade do ensino.

\section{REFERÊNCIAS}

BRASIL. Constituição da República Federativa do Brasil. Brasília, 1988. Constituição (1988).

Decreto no 6.094, de 24 de abril de

2007. Brasília: Diário Oficial [da] República

Federativa do Brasil, 2007. Disponível em: <http://www.planalto.gov.br/ccivil_03/_ato2007-2010/ 2007/decreto/d6094.htm> Acesso em: 10 abr 2021.

Resolução no 2 , de 28 de abril 2008.

Brasília: Diário Oficial [da] República Federativa do Brasil, 2008. Estabelece diretrizes complementares, normas e princípios para o desenvolvimento de políticas públicas de atendimento da Educação Básica do Campo. Disponível em: $<$ http://pronacampo.mec.gov.br/images/pdf/mn 
PROGRAMA CAMINHO DA ESCOLA: IMPACTOS DA POLÍTICA EDUCACIONAL NOS ÍNDICES EDUCACIONAIS RURAIS DO ESTADO DO CEARÁ

resolucao_2_de_28_de_abril_de_2008.pdf>. Acesso em: 10 abr 2021.

Resolução no 426/2008, de 27 de agosto de 2008. Fortaleza: Diário Oficial do Estado do Ceará, 2008. Regulamenta a Educação Básica na Escola do Campo, no âmbito do Estado do Ceará. Disponível em: <https://www.cee.ce.gov.br/wpcontent/uploads/sites/ 49/2011/08/RESOLUCaO-No-426-2008.pdf> Acesso em: 08 abr 2021.

Decreto $\mathrm{n}^{0}$ 6.768, de 11 de fevereiro de 2009. Brasília: Diário Oficial [da] República Federativa do Brasil, 2009. Disciplina o Programa Caminho da Escola. Disponível em: <http://www.planalto.gov.br/ ccivil_03/_ato2007-2010/2009/decreto/d6768.htm> Acesso em: 10 abr 2021.

Lei $n^{\circ}$ 13.005, de 25 junho de 2014. Brasília: Diário Oficial [da] República Federativa do Brasil, 2014. Aprova o Plano Nacional de Educação PNE e dá outras providências. Disponível em: <http://www.planalto.gov.br/ccivil_03/_ato2011-2014/ 2014/lei/113005.htm> Acesso em: 16 abr 2021.

CARVALHO, W. L.; CRUZ, R. O. M. da; CÂMARA, M. T.; ARAGÃO, J. J. G. de. Rural school transportation in emerging countries: The brazilian case. Research in transportation economics, Elsevier, v. 29, n. 1, p. 401-409, 2010.

EGAMI, C. Y.; SOUZA, R. d. A.; MAGALHÃES, M. T. Q.; COSTA, E.; ALVES, M. F. B.; YAMASHITA, Y. Panorama das políticas públicas do transporte escolar rural. In: Congresso de Ensino e Pesquisa em Transportes. Brasília: Universidade de Brasília, 2015. v. 20 .

FNDE. Sobre o Caminho da Escola: o que é? Brasília: FUNDO NACIONAL DE DESENVOLVIMENTO DA EDUCAÇÃO, 2021. Disponível em: <https://www.fnde.gov. br/index.php/programas/caminho-da-escola/ sobre-o-plano-ou-programa-suple/manuais-cartilhas> Acesso em: 10 abr 2021.

INEP. Censo da educação básica 2019: resumo técnico. Brasília: INSTITUTO NACIONAL DE ESTUDOS E PESQUISAS EDUCACIONAIS ANÍSIO TEIXEIRA, 2020. Disponível em: <http: //portal.inep.gov.br/informacao-da-publicacao/-/asset_ publisher/6JYIsGMAMkW1/document/id/6874720> Acesso em: 07 abr 2021.

KUSNIEWSKI, F. P. P. Agroecologia e educação do campo: meios de promover a permanência do jovem no campo? Dissertação (Mestrado em Agroecologia e Desenvolvimento Rural Sustentável) - Universidade Federal da Fronteira Sul, Laranjeiras do Sul, 2018. $141 \mathrm{f}$.

LEHER, R. Pac, educação e heteronomia cultural. Revista de Políticas Públicas, Universidade Federal do Maranhão, v. 11, n. 1, p. 9-33, 2007.

PALUDO, C.; SOUZA, M. A. de; BELTRAME, S. A. B. Escolas do campo na região sul do brasil: primeiras aproximações a partir do ideb. Educação em Perspectiva, v. 6, n. 2, p. 290-316, 2015.

PERGHER, C. J. Política de transporte escolar rural no Rio Grande do Sul: configuração de competências e de relações (inter) governamentais na oferta e no financiamento. Tese (Doutorado em Educação) - Universidade Federal do Rio Grande do Sul, Porto Alegre, 2014. $240 \mathrm{f}$.

SAVIANI, D. O plano de desenvolvimento da educação: análise do projeto do mec. Educação \& Sociedade, SciELO Brasil, v. 28, n. 100, p. 1231-1255, 2007.

SILVA, A. R. d. Metodologia para avaliação e distribuição de recursos para o transporte escolar rural. Tese (Doutorado em Transportes) Universidade de Brasília, Brasília, 2009. 177 f.

TORRES, M. R. Educação do campo: por uma superação da Educação Rural no Brasil. Paraná: Universidade Federal do Paraná, 2017. Disponível em: <https: //www.acervodigital.ufpr.br/handle/1884/38662> Acesso em: 08 abr 2021.

UFG. Avaliação Nacional do Programa Caminho da Escola: avaliação de impacto. Goiás: Universidade Federal de Goiás, 2018. Centro Colaborador de Apoio ao Transporte: Fundação Nacional de Desenvolvimento da Educação. Disponível em: <https://www.fnde. gov.br/index.php/programas/caminho-da-escola/ sobre-o-plano-ou-programa-suple/manuais-cartilhas $>$. Acesso em: 17 abr 2021.

Caracterização e avaliação do transporte escolar do Brasil. Goiás, 2018. Centro Colaborador de Apoio ao Transporte: Fundação Nacional de Desenvolvimento da Educação. 